\title{
Identification of risk factors for pancreatic pseudocysts formation, intervention and recurrence: a 15-year retrospective analysis in a tertiary hospital in China
}

Jie-hui Tan, Lei Zhou, Rong-chang Cao and Guo-wei Zhang*

\begin{abstract}
Background: Pancreatic pseudocyst (PPC) is a common complication of acute and chronic pancreatitis. To our knowledge no study has systematically reported the risk factors for the formation, intervention and recurrence of PPC. Therefore, the present study aimed to investigate the potential risk factors for PPC, with regards to its formation, intervention and recurrence.

Methods: A database containing 5106 pancreatitis patients was retrospectively analyzed. As a result, a total of 4379 eligible patients were identified and divided into 2 groups: PPC group (group $A, n=759$ ) and non-PPC group (group $B, n$ = 3620). The PPC group was subdivided into 2 groups: intervention PPC (group $C, n=347$ ) and resolution PPC (group $D$, $n=412$ ). The differences in surgical complication and recurrence rates were compared among 347 PPC patients receiving different interventions, including surgical, endoscopic and percutaneous drainages. Furthermore, group C was subdivided into 2 groups: recurrent PPC (group $E, n=34$ ) and non-recurrent PPC (group $F, n=313$ ). All possible risk factors for PPC formation, intervention and recurrence were determined by multivariate regression analysis.

Results: In this study, PPC was developed in 17.3\% (759/4379) of pancreatitis patients. The significant risk factors for PPC formation included alcoholic pancreatitis $(\mathrm{OR}, 6.332 ; 95 \% \mathrm{Cl}, 2.164-11.628 ; p=0.031)$, chronic pancreatitis (CP) (OR, 5.822; $95 \% \mathrm{Cl}, 1.921-10.723 ; p=0.006)$ and infected pancreatic necrosis $(\mathrm{OR}, 4.253 ; 95 \% \mathrm{Cl}, 3.574-7.339 ; p=0.021)$. Meanwhile, the significant risk factors of PPC patients who received intervention were alcoholic pancreatitis $(\mathrm{OR}, 7.634 ; 95 \% \mathrm{Cl}, 2.125-$ 13.558; $p=0.016)$, size over $6 \mathrm{~cm}(\mathrm{OR}, 8.834 ; 95 \% \mathrm{Cl}, 2.017-16.649 ; p=0.002)$ and $\mathrm{CP}(\mathrm{OR}, 4.782 ; 95 \% \mathrm{Cl}, 1.897-10.173$; $p=0.038)$. In addition, the recurrence rate in PPC patients treated with percutaneous drainage was found to be the highest (16.3\%) among the three intervention groups. Furthermore, percutaneous drainage was the only risk factor of PPC recurrence $(\mathrm{OR}, 7.812 ; 95 \% \mathrm{Cl}, 3.109-23.072 ; p=0.013)$ identified from this retrospective cohort study.

Conclusions: Alcoholic pancreatitis and CP are the main risk factors for PPC formation and intervention, but not PPC recurrence. A higher recurrence rate is found in PPC patients treated with percutaneous drainage, as compared to endoscopic and surgical interventions.
\end{abstract}

Keywords: Pancreatic pseudocyst, Alcoholic, Pancreatitis, Outcome, Intervention

\footnotetext{
* Correspondence: guoweizhang77@163.com

Department of Hepatobiliary Surgery, Nanfang Hospital, Southern Medical

University, No.1838, North Guangzhou Avenue, Guangzhou 510515, People's

Republic of China
}

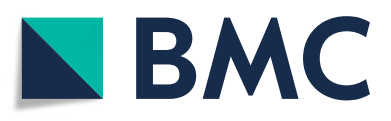

(c) The Author(s). 2018 Open Access This article is distributed under the terms of the Creative Commons Attribution 4.0 International License (http://creativecommons.org/licenses/by/4.0/), which permits unrestricted use, distribution, and reproduction in any medium, provided you give appropriate credit to the original author(s) and the source, provide a link to the Creative Commons license, and indicate if changes were made. The Creative Commons Public Domain Dedication waiver (http://creativecommons.org/publicdomain/zero/1.0/) applies to the data made available in this article, unless otherwise stated. 


\section{Background}

According to the revised Atlanta classification [1], acute fluid collections and pseudocyst formation are the most common complications in patients with acute and chronic pancreatitis. A cute peripancreatic fluid collections often lack a wall of granulation or fibrous tissue, which occurred in $30 \%$ to $50 \%$ of acute pancreatitis (AP) patients within $48 \mathrm{~h}$ of AP onset. More than $50 \%$ of AP cases disappear spontaneously, or develop into PPC surrounded by a well-defined wall [2]. PPC incidence ranged from 5 to $16 \%$ in AP patients, while $20-40 \%$ in patients with CP [3-6].

Large PPC is uaually known to cause compressive symptoms and a variety of treatment methods has been proposed such as conservative treatment (watchful monitoring), surgical drainage (open or laparoscopic), percutaneous drainage and endoscopic drainage. Traditionally, the indications for therapeutic intervention of PPC are more than $6 \mathrm{~cm}$ in size and persisted for more than 6 weeks. In practice, large pseudocysts are less likely to resolve spontaneously. However, prolonged observation of spontaneous PPC resolution may expose patients to unwarranted risks, including bleeding, perforation, jaundice and infection. Therefore, in order to design effective treatment strategies for patients with PPC, clinical studies should be performed on the basis of an appropriate plan of investigation reflecting the latest scientific and technical knowledge.

To our knowledge, after implementation of the 2012 revised Atlanta classification for AP, the number of retrospective studies focusing on PPC is relatively limited, and most of them has become obsolete. Given these circumstances, further studies are warranted to systematically sought out the incidence, risk factors and intervention effect for PPC. Accordingly, this study aimed to identify the potential risk factors for $\mathrm{PPC}$, with regards to its formation, intervention and recurrence.

\section{Methods}

\section{Patient identification and selection}

A total of 5106 pancreatitis patients (4213 AP cases, 526 CP cases and 367 traumatic pancreatitis cases) hospitalized at NanFang Hospital, Southern Medical University from November 2003 to February 2018 were retrospectively analyzed. All patients were diagnosed and treated according to the guidelines of the Pancreatic Surgical Science Section of the Chinese Medical Association Surgery Branch in 2014, and were graded according to the 2012 revised Atlanta classification for AP. According to the 2012 revised Atlanta classification for AP, severity is classified as mild, moderate or severe. Mild acute pancreatitis has no organ failure, local or systemic complications. Moderately severe acute pancreatitis is defined by the presence of transient organ failure, local complications or exacerbation of co-morbid disease. Severe acute pancreatitis is defined by persistent organ failure, that is, organ failure $>48 \mathrm{~h}$ [7]. All interventions were performed by or under the supervision of consultant surgeons and their assistants. PPC resection and cyst-enteric bypass were the primary treatment methods in these patients. The study protocol was approved by the ethics committee of the same hospital.

Among these patients, 4379 pancreatitis cases fulfilled the in-teamed standard and were divided into PPC group (group A, $n=759$ ) and non-PPC group (group $\mathrm{B}, n=$ 3620). PPC was defined according to the revised Atlanta criteria. Group A was further divided into 2 groups: intervention PPC (group C, $n=347$ ) and resolution PPC (group $\mathrm{D}, n=412)$. Similarly, group $\mathrm{C}$ was divided into 2 groups: recurrent PPC (group $\mathrm{E}, n=34$ ) and non-recurrent $\mathrm{PPC}$ (group F, $n=313$ ) (Fig. 1). All PPC patients were followed up for at least 6 weeks after diagnosis, while all intervention patients were followed up for at least 3 months after treatment.

\section{Statistical analysis}

All statistical analyses were performed with SPSS software (SPSS version 22.0, Chicago, IL, USA). Inter-group comparisons were determined by Pearson's chi-square test, Student $\mathrm{t}$ test or Mann-Whitney U test, whenever appropriate. Univariate and multivariate logistic regression analyses were used to investigate the risk factors for the formation, intervention and recurrence of PPC. $P$ values of less than 0.05 were considered statistically significant.

\section{Results}

The clinical characteristics of the 4379 pancreatitis patients are summarized in Table 1. PPC was developed in $17.3 \%(759 / 4379)$ of pancreatitis patients. Intriguingly,

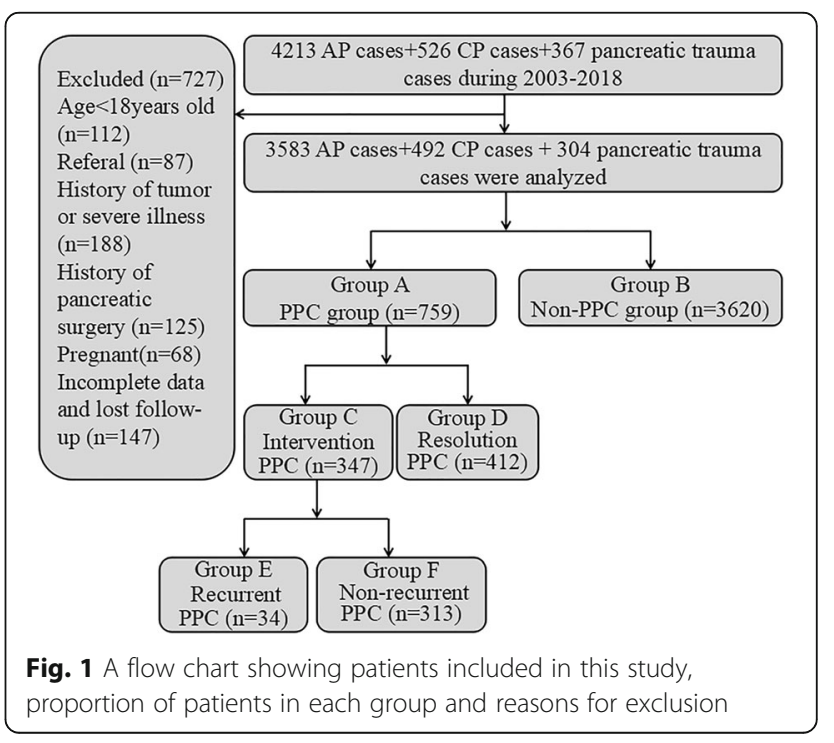


Table 1 Univariate and multivariate regression analyses of risk factors associated with PPC formation

\begin{tabular}{|c|c|c|c|c|c|c|}
\hline \multirow[t]{2}{*}{ Variable } & \multicolumn{4}{|l|}{ Univiarite analysis } & \multicolumn{2}{|l|}{ Multivariate analysis } \\
\hline & Total $(n=4379)$ & Group A $(n=759)$ & Group B $(n=3620)$ & $P$-value & OR $(95 \% \mathrm{Cl})$ & $P$-value \\
\hline Age (years) & $47.82 \pm 15.31$ & $47.33 \pm 14.65$ & $48.12 \pm 15.74$ & 0.523 & & \\
\hline Sex (male/female) & 2788/1591 & $435 / 324$ & $2253 / 1467$ & 0.096 & & \\
\hline BMI & $24.71 \pm 4.85$ & $24.28 \pm 4.76$ & $23.87 \pm 5.13$ & 0.329 & & \\
\hline Smoking (yes/no) & $1343 / 3036$ & $252 / 507$ & $1091 / 2529$ & 0.096 & & \\
\hline \multicolumn{7}{|l|}{ Comorbidity } \\
\hline Hypertension & 425 & 78 & 347 & 0.559 & & \\
\hline Diabetes & 505 & 83 & 412 & 0.724 & & \\
\hline Respiratory diseases & 214 & 35 & 179 & 0.698 & & \\
\hline Liver diseases & 147 & 34 & 113 & 0.061 & & \\
\hline Pancreatitis (acute/chronic) & $3887 / 492$ & $654 / 105$ & $3233 / 387$ & $0.013^{\mathrm{a}}$ & $5.822(1.921-10.723)$ & $0.006^{\mathrm{a}}$ \\
\hline Recurrent pancreatitis (yes/no) & $861 / 3518$ & $143 / 616$ & $718 / 2917$ & 0.565 & & \\
\hline \multicolumn{7}{|l|}{ Symptoms } \\
\hline Pain & 4334 & 748 & 3586 & $0.028^{\mathrm{a}}$ & $1.557(0.891-3.425)$ & 0.067 \\
\hline Fever & 751 & 112 & 639 & 0.054 & & \\
\hline \multicolumn{7}{|l|}{ Etiology } \\
\hline Biliary & 1923 & 354 & 1569 & 0.096 & & \\
\hline Alcoholic & 785 & 163 & 622 & $0.005^{\mathrm{a}}$ & $6.332(2.164-11.628)$ & $0.031^{\mathrm{a}}$ \\
\hline Trauma & 304 & 42 & 262 & 0.093 & & \\
\hline Hyperglycemia & 342 & 49 & 293 & 0.126 & & \\
\hline Post ERCP & 577 & 84 & 493 & 0.059 & & \\
\hline Idiopathic & 448 & 67 & 381 & 0.161 & & \\
\hline \multicolumn{7}{|l|}{ Lab examination } \\
\hline Amylase (U/L) & $859.37 \pm 612.35$ & $831.22 \pm 579.28$ & $864.19 \pm 634.56$ & 0.574 & & \\
\hline WBC $\left(10^{9} / L\right)$ & $13.79 \pm 7.36$ & $14.58 \pm 8.24$ & $12.46 \pm 7.10$ & 0.218 & & \\
\hline CRP (mg/L) & $82.63 \pm 28.52$ & $86.48 \pm 32.67$ & $78.44 \pm 26.36$ & 0.227 & & \\
\hline TBIL (umol/L) & $52.21 \pm 33.62$ & $54.37 \pm 36.27$ & $51.46 \pm 31.70$ & 0.232 & & \\
\hline IPN (\%) & $337(7.7)$ & $78(10.3)$ & $259(7.2)$ & $0.003^{a}$ & 4.253 (3.574-7.339) & $0.021^{a}$ \\
\hline Antibiotics (Yes/No) & $3782 / 592$ & $644 / 115$ & $3138 / 477$ & 0.152 & & \\
\hline Somatostatin (Yes/No) & $4201 / 178$ & $725 / 34$ & $3476 / 144$ & 0.525 & & \\
\hline
\end{tabular}

Data are expressed as $\mathrm{n}(\%)$ or mean \pm standard

${ }^{\text {a }}$ Statistically significant results $(P<0.050)$

alcoholic etiology (OR, 6.332; 95\% CI, 2.164-11.628; $p=$ 0.031), CP (OR, 5.822; 95\% CI, 1.921-10.723; $p=0.006$ ) and infected pancreatic necrosis (IPN) (OR, 4.253; 95\% CI, 3.574-7.339; $p=0.021)$ were revealed as significant risk factors for PPC formation (Table 1). Through multivariate analysis, the independent risk factors for PPC patients who required intervention were found to be alcoholic etiology (OR, 7.634; 95\% CI, 2.125-13.558; $p=0.016$ ), CP (OR, 4.782; 95\% CI, 1.897-10.173; $p=0.038)$ and size over $6 \mathrm{~cm}$ (OR, 8.834; 95\% CI, 2.017-16.649; $p=0.002$ ) (Table 2). Additionally, there were statistically significant differences in the recurrence rates among endoscopic, surgical and percutaneous drainage groups, but not complications. The recurrence rate of PPC treated with percutaneous drainage was $16.3 \%$, which ranked the highest among the three intervention groups (Table 3). Notably, percutaneous drainage (OR, 7.812; 95\% CI, 3.109-23.072; $p=0.013$ ) was the only independent risk factor for PPC recurrence, as assessed by multivariate analysis (Table 4).

\section{Discussion}

PPC, a begin complication of pancreatitis, can be predictors of a malignant outcome, especially among patients with severe AP. The two main indications for some type of invasive drainage procedure are persistent patient symptoms or the presence of complications such as bleeding, infection, gastric outlet and biliary obstruction [8]. To date, the guidelines on minimally invasive management of 
Table 2 Univariate and multivariate regression analyses of risk factors associated with PPC which needs intervention

\begin{tabular}{|c|c|c|c|c|c|}
\hline \multirow[t]{2}{*}{ Variable } & \multicolumn{3}{|l|}{ Univiarite analysis } & \multicolumn{2}{|l|}{ Multivariate analysis } \\
\hline & Group C $(n=347)$ & Group D $(n=412)$ & $P$-value & OR $(95 \% \mathrm{Cl})$ & $P$-value \\
\hline Age (years) & $46.85 \pm 15.19$ & $48.04 \pm 14.27$ & 0.264 & & \\
\hline Sex (male/female) & 193/154 & $242 / 170$ & 0.387 & & \\
\hline BMI & $24.59 \pm 4.62$ & $24.13 \pm 4.83$ & 0.614 & & \\
\hline Smoking (yes/no) & $115 / 232$ & $137 / 275$ & 0.974 & & \\
\hline \multicolumn{6}{|l|}{ Comorbidity } \\
\hline Hypertension & $32 / 315$ & $46 / 366$ & 0.380 & & \\
\hline Diabetes & $39 / 308$ & $44 / 368$ & 0.806 & & \\
\hline Respiratory diseases & $13 / 336$ & $22 / 390$ & 0.289 & & \\
\hline Liver diseases & $14 / 333$ & 20/392 & 0.586 & & \\
\hline Pancreatitis (acute/chronic) & $285 / 62$ & $369 / 43$ & $0.003^{\mathrm{a}}$ & $4.782(1.897-10.173)$ & $0.038^{\mathrm{a}}$ \\
\hline Recurrent pancreatitis (yes/no) & $68 / 279$ & $75 / 337$ & 0.625 & & \\
\hline \multicolumn{6}{|l|}{ Symptoms } \\
\hline Pain & 341 & 407 & 0.554 & & \\
\hline Fever & 48 & 64 & 0.510 & & \\
\hline \multicolumn{6}{|l|}{ Etiology } \\
\hline Biliary & 149 & 205 & 0.061 & & \\
\hline Alcoholic & 89 & 74 & $0.010^{\mathrm{a}}$ & $7.634(2.125-13.558)$ & $0.016^{\mathrm{a}}$ \\
\hline Trauma & 18 & 24 & 0.701 & & \\
\hline Hyperglycemia & 23 & 26 & 0.859 & & \\
\hline Post ERCP & 37 & 47 & 0.745 & & \\
\hline Idiopathic & 31 & 36 & 0.905 & & \\
\hline \multicolumn{6}{|l|}{ Lab examination } \\
\hline Amylase (U/L) & $912.47 \pm 674.63$ & $819.23 \pm 626.37$ & 0.172 & & \\
\hline WBC $\left(10^{9} / \mathrm{L}\right)$ & $14.71 \pm 8.65$ & $13.85 \pm 8.23$ & 0.384 & & \\
\hline CRP (mg/L) & $82.05 \pm 28.39$ & $88.72 \pm 31.33$ & 0.271 & & \\
\hline TBIL (umol/L) & $56.42 \pm 34.71$ & $52.93 \pm 38.37$ & 0.325 & & \\
\hline Time from pancreatitis to pseudocyst (weeks) & $8.47 \pm 1.78$ & $9.12 \pm 2.05$ & 0.311 & & \\
\hline Location & & & $0.043^{\mathrm{a}}$ & $2.534(0.892-3.665)$ & 0.083 \\
\hline Head & 129 & 183 & & & \\
\hline Body/Tail & 218 & 229 & & & \\
\hline Number & & & $0.037^{a}$ & $2.754(0.821-4.378)$ & 0.064 \\
\hline Single & 183 & 186 & & & \\
\hline Multiple & 164 & 226 & & & \\
\hline Size & & & $0.011^{\mathrm{a}}$ & 8.834 (2.017-16.649) & $0.002^{\mathrm{a}}$ \\
\hline$\geq 6 \mathrm{~cm}$ & 144 & 134 & & & \\
\hline$<6 \mathrm{~cm}$ & 203 & 278 & & & \\
\hline IPN & 44 & 34 & $0.045^{\mathrm{a}}$ & $1.811(0.893-3.552)$ & 0.056 \\
\hline Antibiotics (Yes/No) & $302 / 45$ & $342 / 70$ & 0.124 & & \\
\hline Somatostatin (Yes/No) & $331 / 16$ & $394 / 18$ & 0.872 & & \\
\hline
\end{tabular}

Data are expressed as $\mathrm{n}(\%)$ or mean \pm standard ${ }^{a}$ Statistically significant results $(P<0.050)$ 
Table 3 Comparison of complications of 347 PPC intervention patients according to different intervention methods

\begin{tabular}{lllll}
\hline Total $(n=347)$ & Endoscopic & Surgical & Percutaneous drainage \\
& 48 & 164 & 135 \\
\hline Infection & 5 & 13 & 22 & 0.076 \\
Hemorrhage & 2 & 5 & 5 & 0.914 \\
Anastomotic/Percutaneous Leakage & 3 & 4 & 7 & 0.342 \\
Pancreatitis exacerbation & 2 & 2 & 1 & 0.219 \\
Organ failure & 1 & 2 & 3 & 0.906 \\
Mortality & 1 & 1 & 22 & 0.464 \\
Recurrence & 4 & 8 & 22 & $0.004^{\mathrm{a}}$ \\
\hline
\end{tabular}

${ }^{\mathrm{a} S t a t i s t i c a l l y ~ s i g n i f i c a n t ~ r e s u l t s ~}(P<0.050)$

PPC demonstrated a lack of consensus in clinical recommendations, and few recommendations have been graded according to the strength of supporting evidence. The identification and prediction of risk factors for PPC formation, intervention and recurrence may help to distinguish the high-risk PPC group from patients with pancreatitis. Thus, early detection and treatment can be considered for patients at high-risk of PPC. Additionally, identification of risk factors may reduce surgical adverse events, avoid delay in inappropriate interventions and improve the prognosis of PPC patients.

In the present study, data of 5106 pancreatitis patients was retrieved from a prospective database and was retrospectively analyzed. After reviewing the English-language articles published in PubMed with MeSH terms of "pancreatitis", "pancreatic pseudocyst", "pancreatic necrosis", "infected pancreatic necrosis", or "pancreatic fluid collections", we believed that this study contained the largest population of PPC patients at a single center, reporting the risk factors of PPC formation, intervention and recurrence. Alcoholic and chronic pancreatitis remained the main risk factors for PPC formation and intervention. Although the recurrence rate of PPC treated with percutaneous drainage was ranked the highest, there was no difference in the rate of complications among the three types of interventions.

Biliary pancreatitis is ranked the most common cause of PPC among Asian countries, followed by alcoholic pancreatitis. However, more severe forms of AP and local complication, such as pseudocyst formation, have been associated with alcoholic AP compared to biliary AP [9]. Alcohol acts to worsen pancreatitis by its effects on pancreatic mitochondria to promote necrosis, which has been proved by in vitro experiments and clinical research $[10,11]$. Besides, nonalcoholic acute pancreatitis is associated with a lower incidence of pseudocyst formation when compared with acute alcoholic pancreatitis. Alcoholism etiology has been reported as one of the risk factors for pancreatic fluid collections [12]. On the other hand, a high incidence of pseudocyst formation has been found among patients with CP. A multicenter study from China reported that $26.25 \%$ of CP patients are more likely to develop pseudocysts [13]. PPC due to CP, is often accompanied by secondary complications, including duodenal and/or biliary obstruction, splenic vein thrombosis and rarely infection [14]. These complications are primarily treated by surgery and less amenable to endoscopic therapy, especially for common bile duct stricture, main pancreatic duct obstruction and pseudocysts [15]. Furthermore, alcoholism exhibits a worse effect on pancreatic function and is the most common cause of $\mathrm{CP}$. These findings suggest the importance of alcoholic pancreatitis and $\mathrm{CP}$ as new combinational risk factor for PPC formation.

IPN, a local complication of severe AP, is commonly accompanied with PPC, due to the collection of pancreatic necrotic tissues by PPC. Typically, pancreatic necrosis is a late complication of AP, resulting in considerable morbidity and mortality. The necrotic pancreatic tissues can remain solid or liquefy, and remain sterile or become infected. Among the patients with necrotizing pancreatitis, $33 \%$ of them may develop infected necrosis. The prevalence of organ failure in necrotizing pancreatitis is $54 \%$ and even higher among patients with infected necrosis [16]. To the best of our knowledge, no studies have reported on the association between IPN and PPC. The present study revealed that IPN was significantly correlated with PPC formation (OR, 4.253; 95\% CI, 3.574-7.339; $p=0.021$ ). Therefore, it is noted that an active and effective treatment for IPN can prevent the development of PPC, improve the prognosis of pancreatitis patients, and even lower the morbidity and mortality rate.

The surgical techniques and timing of treatment for PPC are still in debate. Most previous studies have shown that PPC larger than 5 or $6 \mathrm{~cm}$ are less likely to resolve spontaneously. The intervention for patients with a small pseudocyst and mild symptoms can be delayed for a further 3 months, since the spontaneous resolution of PPC may still occur [17]. A prolonged period of "wait-and-see" policy for more than 6 weeks is suggested for patients with asymptomatic pseudocyst, especially for a single lesion [6]. Spontaneous resolution has occurred in $40 \%$ to $50 \%$ of 
Table 4 Univariate and multivariate regression analyses of risk factors associated with PPC recurrence

\begin{tabular}{|c|c|c|c|c|c|}
\hline \multirow[t]{2}{*}{ Variable } & \multicolumn{3}{|l|}{ Univiarite analysis } & \multicolumn{2}{|l|}{ Multivariate analysis } \\
\hline & Group E $(n=34)$ & Group F $(n=313)$ & $P$-value & OR $(95 \% \mathrm{Cl})$ & $P$-value \\
\hline Age(years) & $47.33 \pm 15.42$ & $46.42 \pm 14.82$ & 0.317 & & \\
\hline Sex (male/female) & $19 / 15$ & $174 / 139$ & 0.974 & & \\
\hline BMI & $24.12 \pm 4.34$ & $24.69 \pm 4.82$ & 0.538 & & \\
\hline Smoking (yes/no) & $8 / 26$ & $107 / 206$ & 0.210 & & \\
\hline \multicolumn{6}{|l|}{ Comorbidity } \\
\hline Hypertension & 4 & 28 & 0.589 & & \\
\hline Diabetes & 5 & 34 & 0.500 & & \\
\hline Respiratory diseases & 1 & 12 & 0.795 & & \\
\hline Liver diseases & 0 & 14 & 0.208 & & \\
\hline Pancreatitis (acute/chronic) & $27 / 7$ & $258 / 55$ & 0.663 & & \\
\hline Recurrent pancreatitis (yes/no) & $11 / 23$ & $57 / 256$ & $0.048^{\mathrm{a}}$ & $2.017(0.926-4.173)$ & 0.063 \\
\hline \multicolumn{6}{|l|}{ Symptoms } \\
\hline Pain & 33 & 308 & 0.568 & & \\
\hline Fever & 8 & 40 & 0.085 & & \\
\hline \multicolumn{6}{|l|}{ Etiology } \\
\hline Biliary & 13 & 136 & 0.560 & & \\
\hline Alcoholic & 7 & 82 & 0.477 & & \\
\hline Trauma & 3 & 15 & 0.314 & & \\
\hline Hyperglycemia & 2 & 21 & 0.854 & & \\
\hline Post ERCP & 3 & 34 & 0.714 & & \\
\hline Idiopathic & 6 & 25 & 0.061 & & \\
\hline \multicolumn{6}{|l|}{ Lab examination } \\
\hline Amylase (U/L) & $958.26 \pm 662.37$ & $872.51 \pm 652.46$ & 0.142 & & \\
\hline WBC $\left(10^{9} / \mathrm{L}\right)$ & $13.67 \pm 8.24$ & $15.21 \pm 8.32$ & 0.254 & & \\
\hline CRP (mg/L) & $79.32 \pm 27.61$ & $83.23 \pm 29.39$ & 0.371 & & \\
\hline TBIL (umol/L) & $57.72 \pm 33.69$ & $56.10 \pm 35.32$ & 0.652 & & \\
\hline Time from pancreatitis to pseudocyst & $8.74 \pm 2.16$ & $8.37 \pm 1.85$ & 0.725 & & \\
\hline Location & & & 0.099 & & \\
\hline Head & 14 & 115 & & & \\
\hline Body/Tail & 20 & 198 & & & \\
\hline Number & & & 0.325 & & \\
\hline Single & 15 & 168 & & & \\
\hline Multiple & 19 & 145 & & & \\
\hline IPN & 8 & 36 & $0.045^{\mathrm{a}}$ & $1.483(0.875-3.262)$ & 0.083 \\
\hline Antibiotics (Yes/No) & $31 / 3$ & $271 / 42$ & 0.449 & & \\
\hline Somatostatin (Yes/No) & $33 / 1$ & 298/15 & 0.625 & & \\
\hline Intervention methods & & & $0.004^{\mathrm{a}}$ & $7.812(3.109-23.072)$ & $0.013^{\mathrm{a}}$ \\
\hline Endoscopic drainage (\%) & $4(8.3 \%)$ & $44(91.7 \%)$ & & & \\
\hline Surgical drainage (\%) & $8(4.9 \%)$ & $156(95.1 \%)$ & & & \\
\hline Percutaneous drainage (\%) & $22(16.4 \%)$ & $113(83.6 \%)$ & & & \\
\hline
\end{tabular}

Data are expressed as $\mathrm{n}(\%)$ or mean \pm standard

${ }^{a}$ Statistically significant results $(P<0.050)$ 


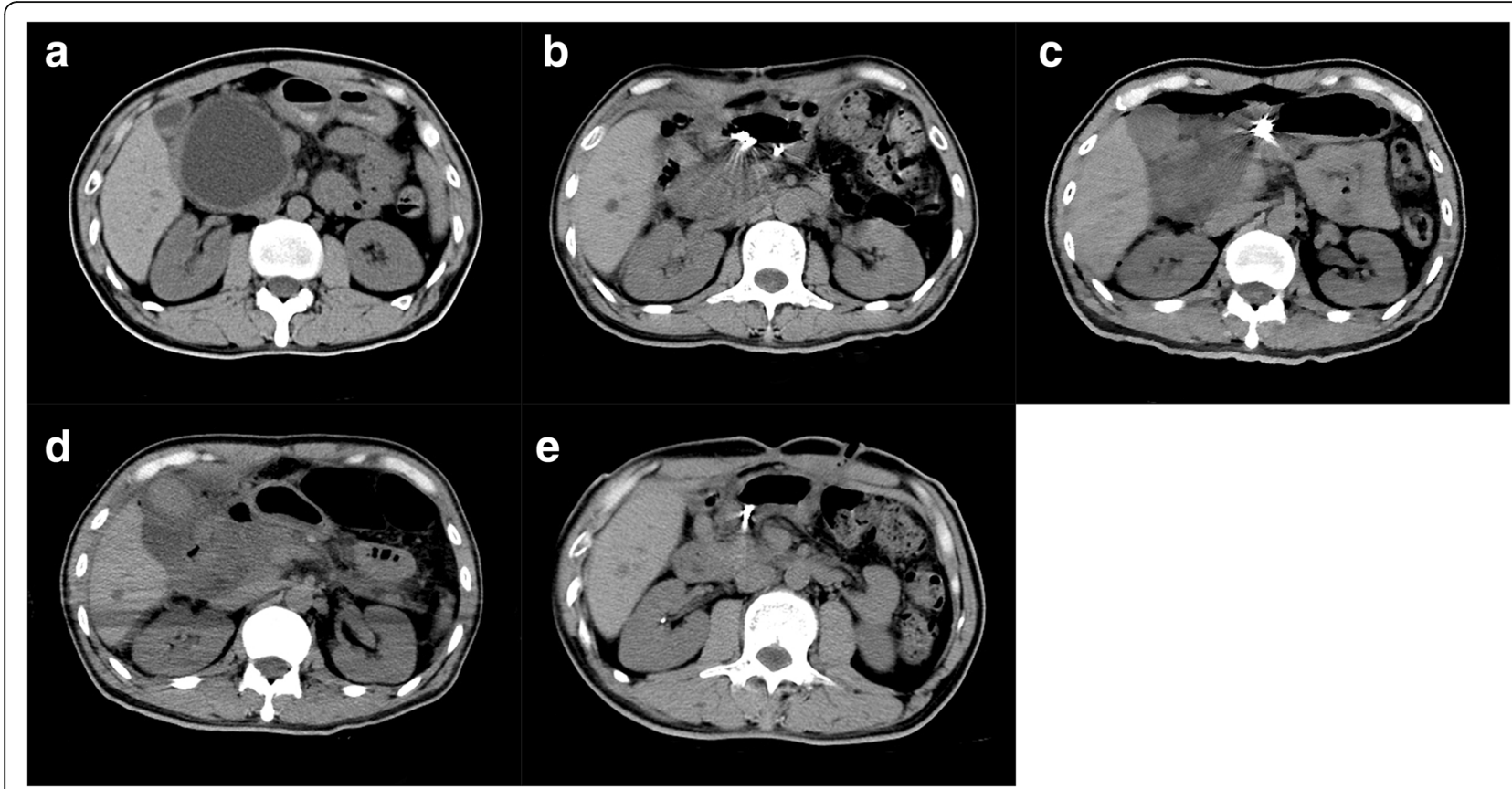

Fig. 2 A PPC case who first received endoscopic cystgastrostomy complicated with anastomotic leakage. The patient received surgical drainage 4 days after endoscopy. a Abdominal CT scan showing a 8-cm PPC; b Pneumoperitoneum occurred on day 1 post-endoscopy; c Seroperitoneum occurred on day 2 post-endoscopy; $\mathbf{d}$ Peritonitis occurred on day 3 post-endoscopy; e Pneumoperitoneum and seroperitoneum disappeared in 1 month since surgical drainage

PPC patients with no major complications during the period of active observation. As a consequence, intervention is warranted if the patient is symptomatic, a progressive increase in PPC size or if complications occur [18]. However, it has been reported that a delay of surgical intervention in PPC may contribute to higher incidences of postoperative complications, readmission, morbidity, and mortality. Moreover, the increasing application of nonsurgical interventions may require a further evaluation [19]. The concept of practice is that the wait-and-see policy should be carried out for more than 4 to 6 weeks until the appearance of spontaneous remission, unless PPC is associated with other symptoms or complications. Generally, chronic pseudocyst encapsulated with a thicker and more well-defined wall than acute pseudocyst [20]. The surgical intervention is usually performed on PPC with a wall thickness of greater than $1 \mathrm{~mm}$. In addition, patients with first-attack AP and fluid collections at discharge should be examined by ultrasonography at a 3-month follow-up, in order to detect the presence of asymptomatic complications such as PPC.

Thus far, there have been no prospective studies comparing the effects of different intervention techniques (i.e. endoscopic drainage, percutaneous drainage and surgical drainage) on the complication and recurrence rates of PPC. The success rate of PPC after endoscopic drainage is considerably variable, most likely due to the presence of heterogeneity among patient populations and intervention types [21]. Surgery is no longer used as a sole treatment for PPC, ever since the emergence of alternative first-line therapy at most centers. Although both endoscopic and surgical drainages have demonstrated comparable success rates, there is a lack of published data regarding the optimal intervention for PPC patients [22]. Some patients may require multiple endoscopic procedures, and the decision to pursue endoscopic therapy depends on patient preference, underlying medical conditions and whether an additional endoscopic procedure is feasible. In addition, percutaneous drainage has been applied in patients with acute pseudocyst or the presence of physiologic exhaustion or comorbid conditions that prevent surgical intervention [23]. Percutaneous drainage provides a convenient alternative to patients, practitioners and physicians. However, several studies reported an equal effectiveness of percutaneous, endoscopic and surgical drainage [22, 24, 25]. In the present study, surgical drainage has the lowest recurrence rate as compared to endoscopic and percutaneous drainages (OR, 7.812; 95\% CI, 3.109-23.072; $p=$ 0.013). For the complication and recurrence rates of PPC among the three intervention groups, surgery is considered as the last remedial step (Figs. 2 and 3). Despite a higher recurrence rate of $\mathrm{PPC}$ in percutaneous drainage group, especially for children, PPC can often be managed without surgery, regardless of its size or complexity [26].

The advancement of new techniques in endoscopic and laparoscopic approaches have reduced the postoperative morbidity and mortality rates of PPC patients. Given that 


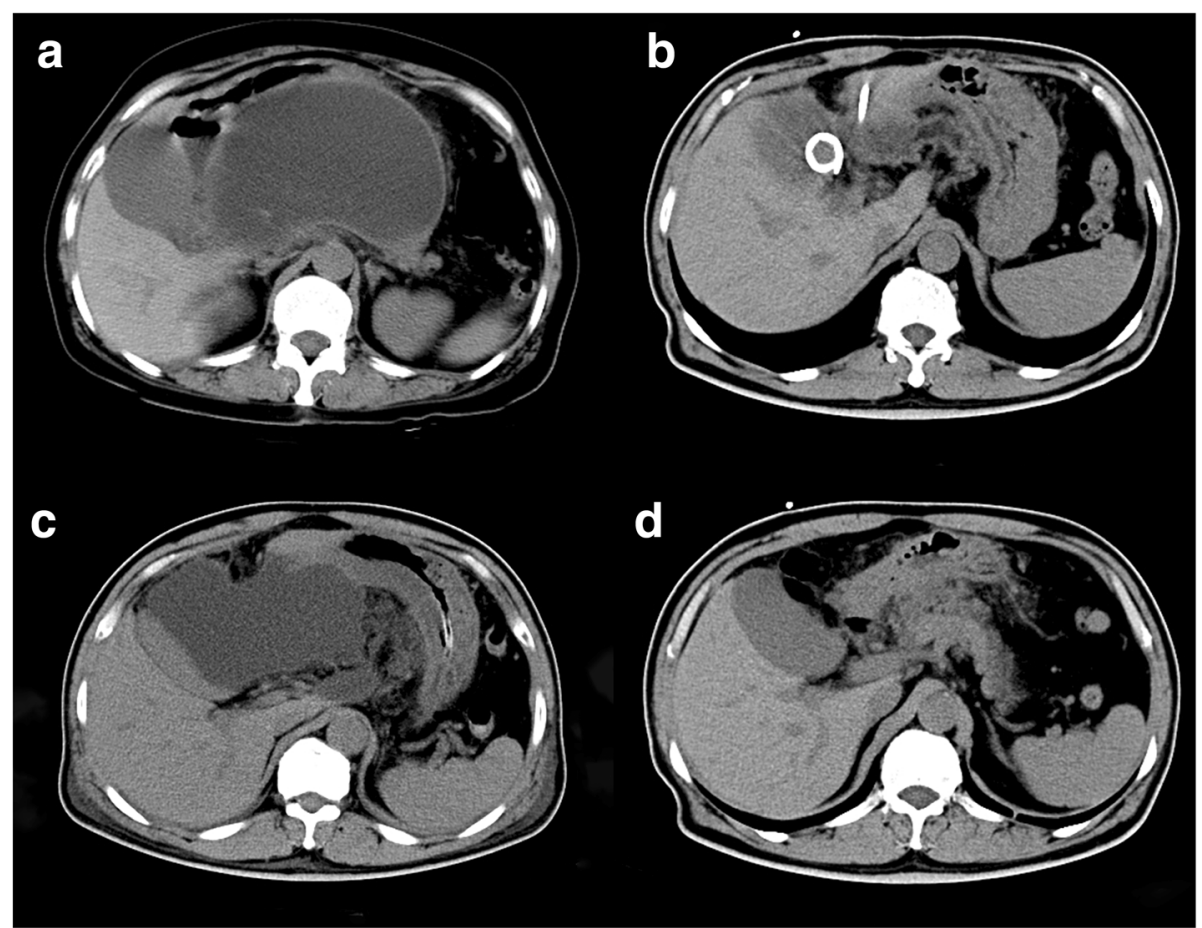

Fig. 3 A PPC case who first received percutaneous drainage recurred, then was cured by surgical drainage. a Abdominal CT scan showing a 13cm PPC; $\mathbf{b}$ PPC resolution on day 7 post-percuataneous drainage; $\mathbf{c}$ PPC recurrence in 2 months since percutaneous drainage; $\mathbf{d}$ PPC disappeared in 1 month since surgical drainage

severe complications may occur after the procedure (Fig. 2), endoscopic drainage is recommended to be performed at tertiary-care center, by a surgeon with expertise in pancreatic surgery [27]. Both laparoscopic and open pancreatic cystgastrostomy have high primary success rates than endoscopic internal drainage, although repeated endoscopic cystgastrostomy offers a better success rate for selected PPC patients [28]. There have been various surgical approaches for treating PPC, but none of them are used as gold standards, as the choice of treatment is much dependent on the surgeon's experience and the clinical characteristics of patient. For patients with symptomatic $\mathrm{CP}$, a multidisciplinary approach appears to have low threshold to surgical intervention, since long-term pain relief is accomplished more often after surgical treatment than after endoscopic treatment [29]. Surgical treatment for PPC patients consistes of open and laparoscopic approaches and includes the following: open drainage, cystogastrostomy, cystojejunostomy, distal pancreatectomy, PPC resection and pancreato-jejunostomy [30]. The laparoscopic approach to cystogastrostomy for PPC is associated with a shorter operating time, a smoother and more rapid postoperative recovery, and a shorter length of hospital stay compared to open surgery. Hence, the laparoscopic approach should be considered as the preferred treatment modality for PPC, when laparoscopic expertise is available [31].

\section{Conclusion}

Alcoholic and chronic pancreatitis may serve as the major risk factors for PPC formation and intervention. Moreover, percutaneous drainage is the only independent risk factor for PPC recurrence. The main limitations of this study include its retrospective design and single-institution nature. Therefore, future multi-institutional prospective studies are warranted to provide additional evidence supporting the risk factors for PPC, and the research results should be incorporated into clinical practice guidelines.

\section{Abbreviations \\ AP: Acute pancreatitis; CP: Chronic pancreatitis; IPN: Infected pancreatic necrosis; PPC: Pancreatic pseudocyst}

\section{Funding}

The study was supported by Guangdong Natural Science Foundation (2015A030313279) \& Guangdong Science and Technology Planning Project (2014A030304022) \& Guangdong Science and Technology Planning Project (2015A030302026) \& Southern Medical University Clinical Research Start-up Planning Project (LC2016PY011). The funding body had no role in the design of the study and collection, analysis, and interpretation of data and in writing the manuscript.

\section{Availability of data and materials}

The datasets used and analysed during the current study are available from the corresponding author on reasonable request.

Authors' contributions

TJH participated in the data collection, statistical analysis, and paper writing as first author; ZL and CRC participated in the data collection. ZGW is the 
corresponding author and designed the study and revised the manuscript. All authors approved the final manuscript.

\section{Ethics approval and consent to participate}

Ethics approval for the study was granted by the Medical Ethics Committees of Southern Medical University Nanfang Hospital, and details can be provided by the corresponding author on reasonable request. Consent to participate is not applicable.

\section{Consent for publication}

Not applicable.

\section{Competing interests}

The authors declare that they have no competing interests.

\section{Publisher's Note}

Springer Nature remains neutral with regard to jurisdictional claims in published maps and institutional affiliations.

Received: 30 June 2018 Accepted: 25 September 2018

Published online: 01 October 2018

\section{References}

1. Sarr MG. 2012 revision of the Atlanta classification of acute pancreatitis. Pol Arch Med Wewn. 2013:123(3):118-24.

2. Brun A, Agarwal N, Pitchumoni CS. Fluid collections in and around the pancreas in acute pancreatitis. J Clin Gastroenterol. 2011;45(7):614-25.

3. Baillie J. Pancreatic pseudocysts. Gastrointest Endosc. 2004;59:873-9.

4. Elliott DW. Pancreatic pseudocysts. Surg Clin North Am. 1975;55:339-62.

5. Barthet M, Bugallo M, Moreira LS, Bastid C, Sastre B, Sahel J. Management of cysts and pseudocysts complicating chronic pancreatitis. A retrospective study of 143 patients. Gastroenterol Clin Biol. 1993;17(4):270-6.

6. Kim KO, Kim TN. Acute pancreatic pseudocyst: incidence, risk factors, and clinical outcomes. Pancreas. 2012:41:577-81.

7. Banks PA, Bollen TL, Dervenis C, Gooszen HG, Johnson CD, Sarr MG, |Tsiotos GG, Vege SS. Classification of acute pancreatitis-2012: revision of the Atlanta classification and definitions by international consensus. Gut 2013; 62(1): 102-111.

8. Habashi S, Draganov PV. Pancreatic pseudocyst. World J Gastroenterol. 2009: 15(1):38-47.

9. Cho JH, Kim TN, Kim SB. Comparison of clinical course and outcome of acute pancreatitis according to the two main etiologies: alcohol and gallstone. BMC Gastroenterol. 2015;15:87.

10. Shalbueva N, Mareninova OA, Gerloff A, Yuan J, Waldron RT, Pandol SJ, Gukovskaya AS. Effects of oxidative alcohol metabolism on the mitochondrial permeability transition pore and necrosis in a mouse model of alcoholic pancreatitis. Gastroenterology. 2013;144(2):437-46.

11. Easler JJ, de-Madaria E, Nawaz H, et al. Patients with sentinel acute pancreatitis of alcoholic etiology are at risk for organ failure and pancreatic necrosis: a dual-center experience. Pancreas. 2016:45(7):997-1002.

12. Cui ML, Kim KH, Kim HG, Han J, Kim H, Cho KB, Jung MK, Cho CM, Kim TN Incidence, risk factors and clinical course of pancreatic fluid collections in acute pancreatitis. Dig Dis Sci. 2014;59(5):1055-62.

13. Wang LW, Li ZS, Li SD, Jin ZD, Zou DW, Chen F. Prevalence and clinical features of chronic pancreatitis in China: a retrospective multicenter analysis over 10 years. Pancreas. 2009;38:248-54.

14. Ramsey ML, Conwell DL, Hart PA. Complications of chronic pancreatitis. Dig Dis Sci. 2017;62(7):1745-50

15. Dumonceau JM, Macias-Gomez C. Endoscopic therapy for chronic pancreatitis. World J Gastroenterol. 2013;19(42):7308-15.

16. Lewis A, Partridge B, Haluszka O. The role of endoscopy in the Management of Pancreatic Necrosis. Curr Gastroenterol Rep. 2014;16(9):406.

17. Lankisch PG, Weber-Dany B, Maisonneuve P, Lowenfels AB. Pancreatic pseudocysts: prognostic factors for their development and their spontaneous resolution in the setting of acute pancreatitis. Pancreatology. 2012;12(2):85-90.

18. Gumaste W, Aron J. Pseudocyst management: endoscopic drainage and other emerging techniques. J Clin Gastroenterol. 2010:44(5):326-31.

19. Ito K, Perez A, Ito H, Whang EE. Pancreatic pseudocysts: is delayed surgical intervention associated with adverse outcomes. J Gastrointest Surg. 2007; 11(10):1317-21.
20. Law R, Baron TH. Endoscopic management of pancreatic pseudocysts and necrosis. Expert Rev Gastroenterol Hepatol. 2015:9(2):167-75.

21. Keane MG, Sze SF, Cieplik N, Murray S, Johnson GJ, Webster GJ, Thorburn D, Pereira SP. Endoscopic versus percutaneous drainage of symptomatic pancreatic fluid collections: a 14-year experience from a tertiary hepatobiliary Centre. Surg Endosc. 2016;30(9):3730-40.

22. Johnson MD, Walsh RM, Henderson JM, Brown N, Ponsky J, Dumot J, Zuccaro G, Vargo J. Surgical versus nonsurgical Management of Pancreatic Pseudocysts. Medicine (Baltimore) J Clin Gastroenterol. 2009;43(6):586-90.

23. Cannon JW, Callery MP, Vollmer CM Jr. Diagnosis and Management of Pancreatic Pseudocysts: what is the evidence? J Am Coll Surg. 2009;209(3): 385-93.

24. Rasch S, Nötzel B, Phillip V, Lahmer T, Schmid RM, Algül H. Management of pancreatic pseudocysts-a retrospective analysis. PLoS One. 2017;12(9): e0184374.

25. Baron TH. Endoscopic drainage of pancreatic pseudocysts. J Gastrointest Surg. 2008;12(2):369-72.

26. Russell KW, Barnhart DC, Madden J, Leeflang E, Jackson WD, Feola GP Meyers RL, Scaife ER, Rollins MD. Non-operative treatment versus percutaneous drainage of pancreatic pseudocysts in children. Pediatr Surg Int. 2013;29(3):305-10.

27. Cavallini A, Butturini G, Malleo G, Bertuzzo F, Angelini G, Abu Hilal M, Pederzoli P, Bassi C. Endoscopic transmural drainage of pseudocysts associated with pancreatic resections or pancreatitis: a comparative study. Surg Endosc. 2011;25(5):1518-25.

28. Melman L, Azar R, Beddow K, Brunt LM, Halpin VJ, Eagon JC, Frisella MM, Edmundowicz S, Jonnalagadda S, Matthews BD. Primary and overall success rates for clinical outcomes after laparoscopic, endoscopic, and open pancreatic cystgastrostomy for pancreatic pseudocysts. Surg Endosc. 2009; 23(2):267-71.

29. van der Gaag NA, Gouma DJ, van Gulik TM, Busch OR, Boermeester MA Review article: surgical management of chronic pancreatitis. Aliment Pharmacol Ther. 2007;26(Suppl 2):221-32.

30. Saul A, Ramirez Luna MA, Chan C, Uscanga L, Valdovinos Andraca F, Hernandez Calleros J, Elizondo J, Tellez Avila F. EUS-guided drainage of pancreatic pseudocysts offers similar success and complications compared to surgical treatment but with a lower cost. Surg Endosc. 2016;30(4):1459-65.

31. Khaled YS, Malde DJ, Packer J, Fox T, Laftsidis P, Ajala-Agbo T, De Liguori Carino N, Deshpande R, O'Reilly DA, Sherlock DJ, Ammori BJ. Laparoscopic versus open cystgastrostomy for pancreatic pseudocysts: a case-matched comparative study. J Hepatobiliary Pancreat Sci. 2014;21(11):818-23.
Ready to submit your research? Choose BMC and benefit from:

- fast, convenient online submission

- thorough peer review by experienced researchers in your field

- rapid publication on acceptance

- support for research data, including large and complex data types

- gold Open Access which fosters wider collaboration and increased citations

- maximum visibility for your research: over $100 \mathrm{M}$ website views per year

At $\mathrm{BMC}$, research is always in progress.

Learn more biomedcentral.com/submissions 